\title{
Production of Succinic Acid From Basfia succiniciproducens
}

\author{
Sergio D'ambrosio ${ }^{1}$, Alberto Alfano ${ }^{1}$ and Donatella Cimini ${ }^{2 *}$ \\ ${ }^{1}$ Department of Experimental Medicine, University of Campania L. Vanvitelli, Naples, Italy, ${ }^{2}$ Department of Environmental, \\ Biological and Pharmaceutical Sciences and Technologies, University of Campania L. Vanvitelli, Caserta, Italy
}

OPEN ACCESS

Edited by:

Giuseppe Olivieri,

Wageningen University and Research,

Netherlands

Reviewed by:

Anestis Vlysidis,

Agricultural University of Athens,

Greece

Jianmin Xing,

Institute of Process Engineering (CAS),

China

*Correspondence:

Donatella Cimini

donatella.cimini@unicampania.it

Specialty section:

This article was submitted to

Chemical Reaction Engineering,

a section of the journal

Frontiers in Chemical Engineering

Received: 29 September 2021

Accepted: 05 November 2021

Published: 24 December 2021

Citation:

D'ambrosio S, Alfano A and Cimini D (2021) Production of Succinic Acid

From Basfia succiniciproducens.

Front. Chem. Eng. 3:785691.

doi: $10.3389 /$ fceng.2021.785691
Basfia succiniciproducens is a facultative anaerobic capnophilic bacterium, isolated from rumen, that naturally produces high amounts of succinic acid by fixing $\mathrm{CO}_{2}$ and using fumarate as final electron acceptor. This metabolic feature makes it one of the ideal candidates for developing biotechnological industrial routes that could eventually replace the polluting and environment unfriendly petrochemical ones that are still main sources for the production of this value-added compound. In fact, due to the large number of applications of succinic acid that range from the more traditional ones as food additive or pharmaceutical intermediate to the most recent as building block for biopolymers and bioplastic, increasing demand and market size growth are expected in the next years. In line with a "green revolution" needed to preserve our environment, the great challenge is the establishment of commercially viable production processes that exploit renewable materials and in particular preferably non-food lignocellulosic biomasses and waste products. In this review, we describe the currently available literature concerning $B$. succiniciproducens since the strain was first isolated, focusing on the different renewable materials and fermentation strategies used to improve succinic acid production titers to date. Moreover, an insight into the metabolic engineering approaches and the key physiological characteristics of B. succiniciproducens deduced from the different studies are presented.

Keywords: Basfia succiniciproducens, succinic acid, renewable material, waste, lignocellulose

\section{INTRODUCTION}

Basfia succiniciproducens is a Gram-negative member of the family of Pasteurellaceae and owes its name to the company BASF that first isolated the strain DD1 from the rumen fluid of a cannulated Holston cow and characterized it (Scholten and Dägele, 2008; Scholten et al., 2008; Kuhnert et al., 2010). As other members of this family, it is a capnophilic facultative anaerobic bacterium that has the attractive characteristic of producing significant amounts of succinic acid (SA) in the presence of $\mathrm{CO}_{2}$. The genome of this strain (Scholten and Dägele, 2008) is highly similar to that of Manneheimia succiniciproducens MBEL55E showing the same GC content (42.5\%) and a slightly lower number of ORFs (2,363 vs. 2,380) with an average homology of about $95 \%$ (Ahn et al., 2016). As initially established in small-scale serum bottle experiments on rich (semi-defined) MH medium, the strain is capable of metabolizing different carbon sources among which glucose, sucrose, fructose, mannose, xylose, arabinose, galactose, and glycerol, showing on the latter the highest yield of product on consumed C source $(1.2 \mathrm{~g} / \mathrm{g}$ ), although higher productivities were observed on sucrose and glucose (Scholten and Dägele, 2008). This vast metabolic versatility perfectly fits the need to use waste materials such as lignocellulosic biomasses, discarded molasses, and crude glycerol produced as by-product of diesel 
manufacturing processes, and therefore immediately drew the attention of the scientific community identifying the strain as a promising candidate for bio-succinate production.

SA is a key building block and precursor of several compounds employed in the food, pharmaceutical, and also commodity and specialty chemicals industries. In fact, besides more traditional applications as food additive and pharmaceutical intermediate, it is also used for the production of bio-plastics (e.g., polybutylene succinate), polypolyester polyols, lubricants, etc. Notwithstanding the increasing number of potential applications and the stricter regulatory constrains towards synthetic chemicals, it is clear from a recent analysis of the "global succinic acid status" that the still high manufacturing production costs limit market development in the near future 2021-2027 (Markets Study Report, 2021, https://www. marketstudyreport.com/reports/global-succinic-acid-market-sizeresearch?utm_source=Marketwatchtm.com/\&utm_medium=AK). In fact, it seems that due to the recent drop of the oil price up to 2018, only Reverdia (DSM) out of the four leading companies worldwide that invested in SA production was actively manufacturing (McCoy, 2019). However, BioAmber's manufacturing plant was acquired by LCY Biosciences in 2019, and is now reported to have resumed manufacturing as well, and this also demonstrates the importance and necessity of continuous process optimization to achieve and maintain economic viability.

Therefore, parallel actions are needed to establish competitive production routes, namely, (1) rewiring microbial metabolism to engineer pathways for the maximization of SA production and (2) investing in the study of more sustainable fermentation processes based on the use of renewable raw materials also supporting circular economy. This mini-review will focus on the description of the current published peer-reviewed scientific as well as patent literature on the overall development of engineering strategies and production processes that use $B$. succiniciproducens as host.

\section{METABOLIC ENGINEERING STRATEGIES}

Few examples of $B$. succiniciproducens genome manipulation are reported in the literature (Table 1). In particular, Becker and collaborators (2013) for the first time investigated flux distribution in the central metabolic pathways of wild-type $B$. succiniciproducens growing on a glucose minimal medium, in steady-state conditions. The authors found the presence of a functional TCA cycle, differently from other SA-producing microorganisms such as Actinobacillus succinogenes (McKinlay et al., 2005), mainly operating as two separate branches: the reductive branch that provided $75 \%$ of the flux and an oxidative branch that only marginally contributed to the production of SA (Figure 1).

Differently from M. succiniciproducens (Lee et al., 2006), a significant amount of carbon was diverted to secreted formate and acetate, while less pyruvate was converted to lactic acid (LA) and ethanol. By eliminating $p f D$ and $l d h A$ coding for pyruvate formate lyase and lactate dehydrogenase, the authors enhanced fluxes to SA production, improving by $44 \%$ the $\mathrm{Y}_{\mathrm{p} / \mathrm{s}}$ yield (Becker et al., 2013). Moreover, in contrast to the wild type, the double deletion mutant showed balanced supply and consumption of NADH. Single deletion of $p f D$ engaged only part of the pyruvate for SA production, causing a strong enhancement of LA secretion (Becker et al., 2013). The same genes were previously targeted by Schroder et al. (2010) by means of gene integration with the pSacB vector. The strains were tested on different semi-defined media with glycerol coupled to other sugars, in $100-\mathrm{ml}$ serum bottles $(10 \mathrm{ml}$ medium) with $\mathrm{CO}_{2}$ head overpressure and $30 \mathrm{~g} / \mathrm{l}$ of $\mathrm{MgCO}_{3}$. The $p f l$ $l d h$ double deletion mutant showed the highest yield $\left(\mathrm{Y}_{\mathrm{p} / \mathrm{s}}\right)$ improvement, and a final titer of about $70 \mathrm{~g} / \mathrm{l}$ of SA in the medium.

Since sucrose is an inexpensive feedstock for microbial fermentation although often not used efficiently, its metabolism was investigated by ${ }^{13} \mathrm{C}$ metabolic flux analyses in $B$. succiniciproducens. Interestingly, a unique feature of $B$. succiniciproducens in respect to other Pasteurellaceae is that two enzymes, namely, fructokinase $(r b s K)$ and fructose PTS ( fruA), are both involved in sucrose catabolism and accomplish fructose phosphorylation (Lange et al., 2017). However, differently from fructose PTS, fructokinase does not operate in a PEP-dependent manner, thus avoiding the accumulation of pyruvate-derived byproducts. The deletion of the fruA gene led to a $45 \%$ improvement of the product yield on sucrose and reduced the amount of pyruvatederived by-products (e.g., ethanol, lactic acid, and formic acid). In fed-batch experiments the final concentration of SA only increased by $12 \%$; however, the $\mathrm{Y}_{\mathrm{SA} / \mathrm{SUC}}$ improved by $40 \%$ during the "substrate-accumulating phase", as reported by the authors, and also a reduction of acid by-products confirmed previous results obtained in serum-bottle experiments. Computational modeling allowed the authors to establish that B. succiniciproducens can produce up to $3 \mathrm{~mol}$ of SA per mole of sucrose (Lange et al., 2017).

To improve the efficiency of sucrose catabolism in $B$. succiniciproducens DD1, Krawczyk et al. (2015 a) deleted the $p t s G$ gene encoding a PEP-dependent sucrose permease and expressed a heterologous sucrose hydrolase from $E$. coli $(\csc A)$ thereby increasing SA production from about 22 to almost $36 \mathrm{~g} / \mathrm{l}$; interestingly, also a reduced activity of pyruvate phosphor kinase ( $p y k A)$ in the $p f l A-l d h A$ double deletion strain increased the sucrose volumetric consumption rate from about 1.16 to $3.18 \mathrm{~g} / \mathrm{lh}$ (Krawczyc et al. 2015b).

A slight increase of SA production was also obtained by overexpressing the $\mathrm{NAD}(\mathrm{P})+$-transhydrogenase ( $u d h A)$, from Escherichia coli into $\triangle l d h A \triangle p f l D B$. succiniciproducens DD1 (Boehmer et al., 2019). The authors integrated the heterologous $u d h A$ gene, under control of either gapA or $p c k A$ promoters, in the bioB locus of the host strain. Small-scale main cultures were conducted on complex CGM medium containing glucose as carbon source; on average, a $20 \%$ and $15 \%$ higher concentration of SA and $\mathrm{Y}_{\mathrm{SA} / \mathrm{GLU}}$, respectively, were obtained with the different promoters.

\section{PRODUCTION OF SA FROM RENEWABLE NON-FOOD RESOURCES}

The latest bioeconomy initiatives foresee the replacement of conventional fossil-based resources with renewable feedstocks, and in particular with non-food and organic waste materials. In 
TABLE 1 | Engineering and fermentation strategies used to improve succinic acid production in $B$. succiniciproducens and fermentation processes developed for the production of succinic acid from wild-type $B$. succiniciproducens spp. on renewable materials. N.R., not reported. TA, total acid by-products; Glu, glucose; Gly, glycerol; Suc, sucrose; Mal, maltose; DDAPH, deacetylated dilute acid-pretreated hydrolysate; Xyl, xylose; Fru, fructose; TS, total sugars; SSL, spent sulfite liquor; LS, lignosulfonates. *indicates values deduced from graphs reported in the relative publication or calculated from the yields. Batch: closed process in which all nutrients are added at time zero and all products remain in the bioreactor until the end of the run; Fed-batch, semi-open process, in which after a batch phase nutrients are fed to prolong the growth phase, and all products remain in the bioreactor until the end of the run; Chemostat, open process in which nutrients are continuously added to the reactor and products (and unconsumed nutrients) are removed at the same rate to keep the volume constant.

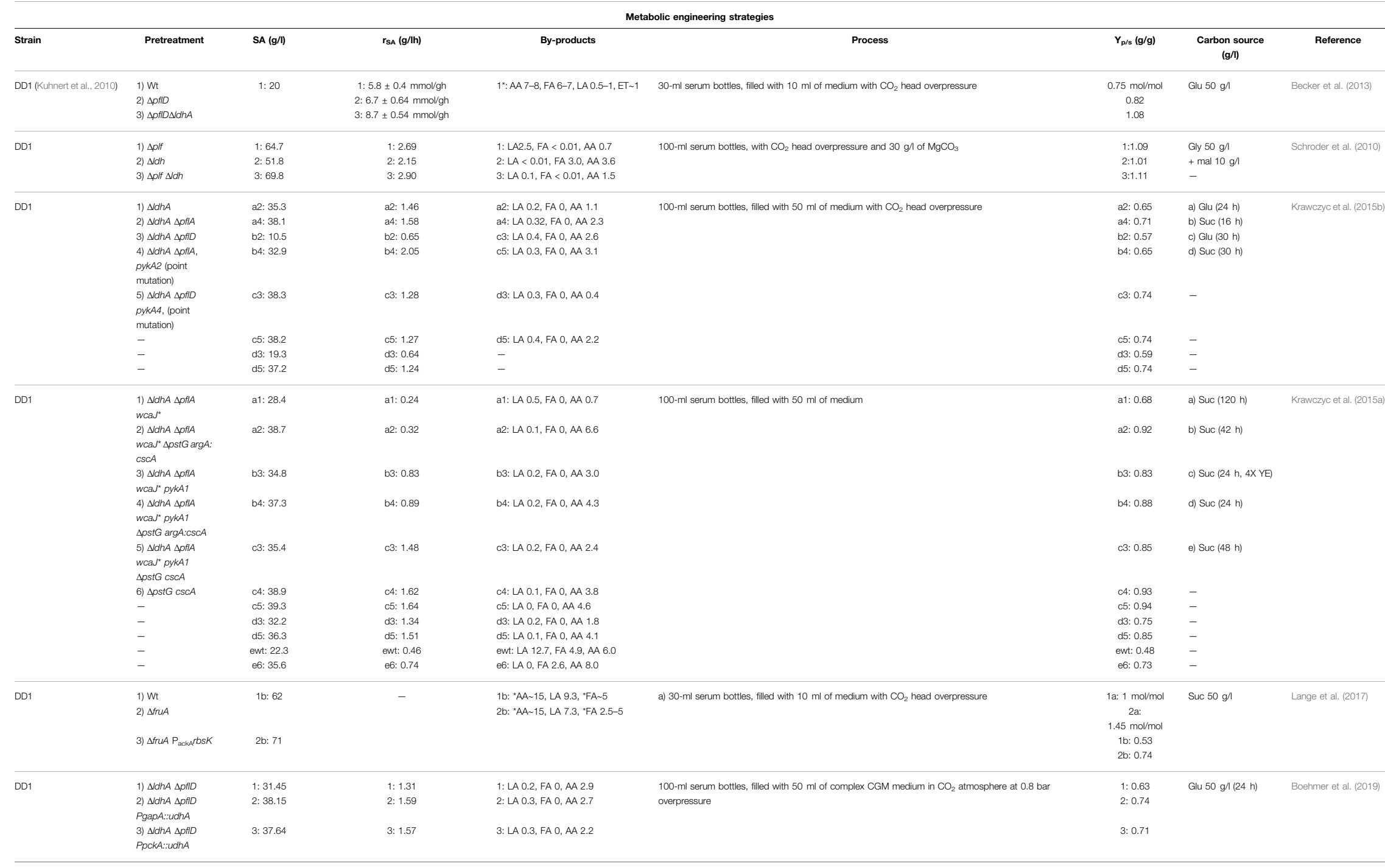


TABLE 1 | (Continued) Engineering and fermentation strategies used to improve succinic acid production in $B$. succiniciproducens and fermentation processes developed for the production of succinic acid from wild-type $B$. succiniciproducens spp. on renewable materials. N.R., not reported. TA, total acid by-products; Glu, glucose; Gly, glycerol; Suc, sucrose; Mal, maltose; DDAPH, deacetylated dilute acid-pretreated hydrolysate; Xyl, xylose; Fru, fructose; TS, total sugars; SSL, spent sulfite liquor; LS, lignosulfonates. *indicates values deduced from graphs reported in the relative publication or calculated from the yields. Batch: closed process in which all nutrients are added at time zero and all products remain in the bioreactor until the end of the run; Fed-batch, semi-open process, in which after a batch phase nutrients are fed to prolong the growth phase, and all products remain in the bioreactor until the end of the run; Chemostat, open process in which nutrients are continuously added to the reactor and products (and unconsumed nutrients) are removed at the same rate to keep the volume constant.

\begin{tabular}{|c|c|c|c|c|c|c|c|c|}
\hline \multicolumn{9}{|c|}{ Wild-type strains on waste materials } \\
\hline Strain & Pretreatment & SA (g/l) & $r_{S A}(g / h)$ & By-products (g/l) & Process & $Y_{p / s}(g / g)$ & Carbon source (g/) & Ref \\
\hline DD1 & - & $\begin{array}{l}\begin{array}{c}1: 35-45 \\
2: 30 \\
3: 12.3(5 \mathrm{~h}) \\
4: 57.54\end{array}\end{array}$ & $\begin{array}{l}3: 2.5 \\
4: 3.4 \\
- \\
-\end{array}$ & $\begin{array}{c}\text { 3: AA 4.5, FA3.3, LAO } \\
\text { 4: FA 3.7, AA 3.41 } \\
- \\
-\end{array}$ & $\begin{array}{l}\text { 1) Batch } 0.31, \mathrm{pH} 6.5,34-39^{\circ} \mathrm{C}, 500 \mathrm{rpm}, 0.1 / \mathrm{min} \mathrm{CO}_{2} \\
\text { 2) Batch } 0.31, \mathrm{pH} 6.5,39^{\circ} \mathrm{C}, 500 \mathrm{rpm}, 0.1 \mathrm{Vmin} \mathrm{CO}_{2} \\
\text { 3) Batch } 0.31, \mathrm{pH} 6.5,39^{\circ} \mathrm{C}, 50 \mathrm{rmm}, 0.2 \mathrm{wmm} \mathrm{CO}_{2} \\
\text { 4) Batch } 1,37^{\circ} \mathrm{C}, \mathrm{pH} 6.5,0.2 \mathrm{wm}, 300 \mathrm{rpm}\end{array}$ & $\begin{array}{l}\text { 1) } 0.5 \\
\text { 2) } 0.6 \\
\text { 3) } 0.7 \\
\text { 4) } 1.2\end{array}$ & $\begin{array}{l}\text { 1) Glu } 75-80 \mathrm{~g} / 1 \\
\text { 2) Corm steep liquor, Glu } 50 \mathrm{~g} / \text {, no YE } \\
\text { 3) Glu } 20 \mathrm{~g} / \\
\text { 4) Mal } 11.2 \mathrm{~g} / \mathrm{Gly} 36.5 \mathrm{~g} / 1\end{array}$ & Scholten et al. (2008) \\
\hline DD1 & - & 5.21 & 0.094 & AA $0.41 \pm 0.03$, LA $0.33 \pm 0.04$ & Chemostat $0.31, \mathrm{pH} 6.5,500 \mathrm{rpm}, 0.1 \mathrm{~V} / \min \mathrm{CO}_{2}, \mathrm{D}=0.018$ & 1.02 & Crude gly (ecoMotion, GmbH Sternberg) & Scholten et al. (2009) \\
\hline CCUG 57335 & $\begin{array}{l}\text { DDAPH } \\
\text {-Deacetylation } \\
(0.4 \% \text { NaOH } \\
\left.2 \mathrm{~h} 80^{\circ} \mathrm{C}\right) \\
\text {-Acid hydrolysis } \\
\left(8 \mathrm{~g} \mathrm{H} \mathrm{SO}_{4} / \mathrm{kg}\right. \\
\text { biom, } 10 \mathrm{~min} \\
\left.\quad 160^{\circ} \mathrm{C}\right)\end{array}$ & $\begin{array}{l}1: 25.9 \pm 0.1 \\
2: 22.1 \pm 0.5 \\
3: 30.6 \pm 0.3 \\
4: 24.1 \pm 0.1\end{array}$ & $\begin{array}{c}1: 0.36 \\
2: 0.31 \\
3: 0.43 \\
4^{*}: 0.33\end{array}$ & 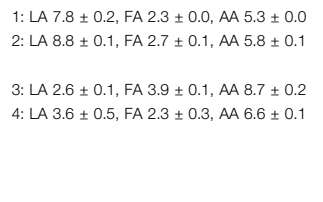 & 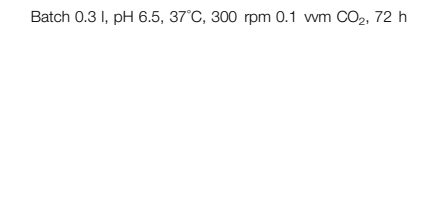 & $\begin{array}{l}\text { 3) } 0.69 \\
\text { 4) } 0.68 \\
-\end{array}$ & $\begin{array}{l}\text { Corn stover hydrolysate DDAPH } \\
\text { 1) Mock DDAPH, Glu } 60 \mathrm{~g} / 1 \\
\text { 2) Mock DDAPH, Glu } 80 \mathrm{~g} / 1 \\
\text { 3) DDPPH tot sugars } 40 \mathrm{~g} / 1 \\
\text { 4) DDAPH tot sugars } 60 \mathrm{~g} / 1\end{array}$ & Salvachúa et al. (2016 \\
\hline BPP7 & $\begin{array}{l}- \text { Soaking } 100 \text { min } \\
160^{\circ} \mathrm{C} \\
- \text { Steam explosion } \\
8 \text { min } 200^{\circ} \mathrm{C} \\
- \text { Sterilization } 1 \mathrm{~h} \\
110^{\circ} \mathrm{C} \\
\text {-Enzymatic } \\
\text { hydrolysis }\end{array}$ & $\begin{array}{l}2: 15-16 \\
-\end{array}$ & $\begin{array}{l}1: 0.35 \\
2: 0.32 \\
- \\
-\end{array}$ & N.R. & $\begin{array}{l}\text { 1) Batch 2.5 I, pH 6.5, } 0.5 \mathrm{wm} \mathrm{CO}_{2} \\
\text { 2) Batch } 70 \text { I, pH 6.5, } 0.1 \mathrm{wm} \mathrm{CO}_{2} \\
- \\
-\end{array}$ & $0.75 \mathrm{mo} / \mathrm{mol}$ & $\begin{array}{l}\text { Arundo donax hydrolysate } \\
\text { 1) Glu } 17 \mathrm{~g} /, \mathrm{xy} 19 \mathrm{~g} / \mathrm{l} \\
\text { 2) Glu } 15 \mathrm{gll,} \text { xyl } 7.5 \mathrm{~g} /\end{array}$ & Cimini et al. (2016) \\
\hline BPP7 & $\begin{array}{l}- \text { Soaking } 100 \text { min } \\
160^{\circ} \mathrm{C} \\
\text {-Steam explosion } \\
8 \text { min } 200^{\circ} \mathrm{C} \\
- \text { Sterlization } 1 \mathrm{~h} \\
110^{\circ} \mathrm{C} \\
\text { Enzzyatic } \\
\text { hydrolysis }\end{array}$ & 37 & 0.9 & :AA 6.3 & Fed-batch 70-80 I, pH 6.5, $0.1 \mathrm{wm} \mathrm{CO} 2$ & 0.9 & $\begin{array}{l}\text { Arundo donax hydrolysate } \\
\text { Glu Feed: } 1 \text { g/h }\end{array}$ & Cimini et al. (2019) \\
\hline BPP7 & $\begin{array}{l}\text {-Steam explosion } \\
8 \text { min } 200^{\circ} \mathrm{C} \\
\text { - Enyymatic } \\
\text { hydrolysis }\end{array}$ & $\begin{array}{l}1: 15-18 \\
2: 6-9\end{array}$ & $\begin{array}{l}1 *: 0.5-0.6 \\
2 *: 0.28\end{array}$ & $\begin{array}{l}\text { 1: *A 5-6 } \\
\text { 2: *A 2-3 }\end{array}$ & Batch $2.4 \mathrm{I}, \mathrm{pH} 6.5,0.5 \mathrm{wm} \mathrm{CO}{ }_{2}$ & 1) 0.75 & $\begin{array}{c}\text { 1) P. nigra } \\
\text { Glu 18-20 g }+x y 12-3 \mathrm{~g} / \\
\text { 2) P. virgatum Glu } 6-7 \mathrm{~g} /+\mathrm{xyl} 1.7-2.4 \mathrm{~g} /\end{array}$ & Pennacchio et al. (2018 \\
\hline JF4016 & $\begin{array}{c}\text {-Mechanical } \\
\text { prectreatment } \\
\text { (homogenization) } \\
\text {-Sterilization } \\
121^{\circ} \mathrm{C}, 1 \mathrm{~h} \\
\text {-Enzymatic } \\
\text { hydrolysis }\end{array}$ & $\begin{array}{l}2: 26.8 \\
3: 37.1\end{array}$ & 2) 0.85 & $\begin{array}{l}2^{*}: \text { TA } 24 \\
3^{*} \text { : TA } 25\end{array}$ & $\begin{array}{c}0.5 \mathrm{wm} \mathrm{CO} \\
-\end{array}$ & 2) 0.53 & $\begin{array}{l}\text { Glu } 25.4-75.9 \mathrm{~g} / 1 \\
\text { Xyl } 3.95-7.6 \mathrm{~g} / 1 \\
\text { Fru } 0.1-15.5 \mathrm{~g} / 1 \\
\text { 1) TS } 30 \mathrm{~g} / \\
\text { 2) TS } 50 \mathrm{~g} / \\
\text { 3) TS } 80 \mathrm{~g} / 1\end{array}$ & Stylianou et al. (2020) \\
\hline DSM22022 & $\begin{array}{l}\text {-Freeze-drying } \\
\text {-Homogenization } \\
\text {-Enzymatic } \\
\text { hydrolysis }\end{array}$ & 4 & N.R. & $\begin{array}{l}\text { "LA } 2 \\
\text { "AA 1-2 } \\
\text { "FA 1-2 }\end{array}$ & $\begin{array}{l}\text { Batch } 1.5 \mathrm{l}, \mathrm{pH} 6.7 \text {, recirculated biogas } \\
\text { Process duration } 12 \mathrm{~h}\end{array}$ & 0.25 & $\begin{array}{l}\text { Organic fraction of housenold kitchen waste } \\
\qquad \begin{array}{l}\text { Gu } 15 \mathrm{~g} / 1 \\
x y 12 \mathrm{~g} / 1\end{array}\end{array}$ & Babaei et al. (2019) \\
\hline
\end{tabular}




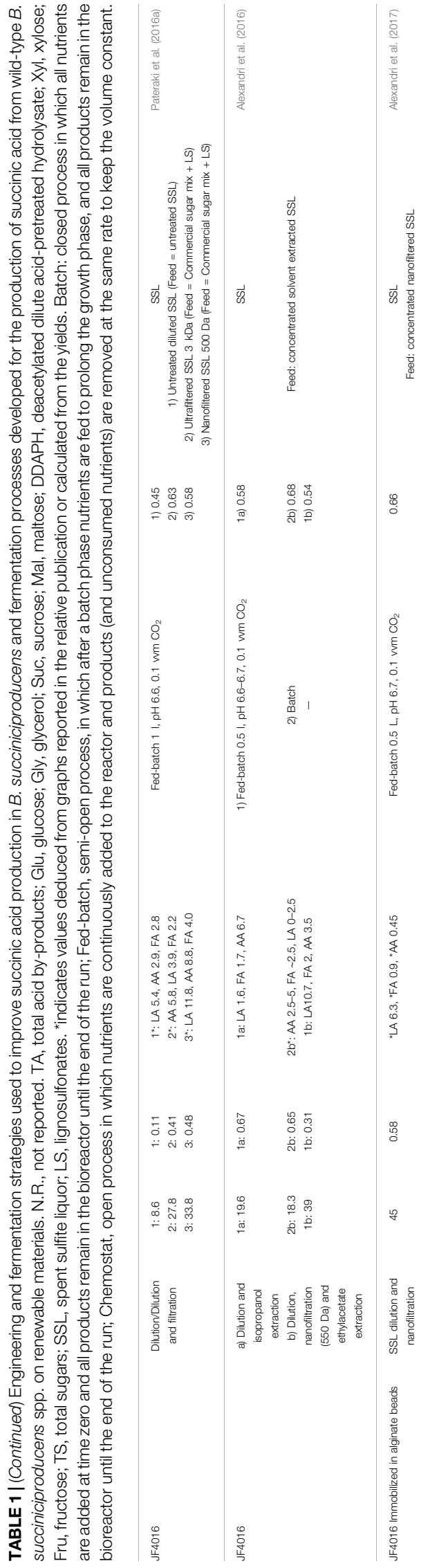

fact, considering the essential need to preserve the environment, it is crucial to fully exploit waste materials not only by converting them into added valued compounds, but also by reducing the number of expensive and polluting disposal processes. In this context, sustainable SA production processes based on renewable substrates is one of the latest goals.

The firstly isolated rod-shaped capnophilic, oxygen-tolerant $B$. succiniciproducens DD1 strain is capable of metabolizing all types of monosaccharides present in lignocellulose (Scholten et al., 2008) and also glycerol, thereby resulting in a promising candidate for industrial production of SA. Considering that substrate costs can account for over $40 \%$ of the overall process expenses, the possibility to use inexpensive non-food resources or waste streams is of foremost importance. An overview of all fermentation processes developed by growing $B$. succiniciproducens on diverse reusable substrates is presented in Table 1 and discussed in the following paragraphs.

\section{Biodiesel-Derived Glycerol}

Besides being a cheap and abundant by-product of biodiesel production, glycerol is a convenient substrate for the production of chemicals, since it possesses carbon in a more reduced state of that in common sugars, thereby resulting in higher product yields (Dharmadi et al., 2006). In fact, Scholten and colleagues obtained the highest $\mathrm{Y}_{\mathrm{SA} / \mathrm{C}}(\mathrm{g} / \mathrm{g})$ on glycerol in comparison to other carbon sources (glucose, sucrose, fructose, xylose, arabinose, galactose, and mannose), also coupled with a considerably lower production of organic acid by-products, in particular acetic and formic acid. By comparing pure glycerol to different crude glycerols, a higher productivity of SA, ranging between 0.7 and $0.9 \mathrm{~g} / \mathrm{lh}$, was observed in $50-\mathrm{ml}$ bottle experiments with the latter (Table 1). Crude glycerol was also used for carbon-limited chemostat cultivations (Scholten et al., 2009) that highlighted a high stability of $B$. succiniciproducens (experiment duration 80 days) and the increase of SA productivity and yield with higher specific growth rates (Scholten et al., 2009). However, for the process to be commercially viable, the titer of SA needs to be substantially increased.

\section{Lignocellulosic Biomass}

Although extraction of fermentable sugars from lignocellulosic matrices is quite challenging and often results in low yields, growth of B. succiniciproducens was evaluated on diverse biomass hydrolysates. Besides identifying process conditions to digest cellulose and hemicellulose fibers, aggressive pretreatments that de-structure the lignocellulose and give access to the carbohydrates, are necessary. These cause the release of acetate, furans, and phenolic compounds that can inhibit cell growth. However, A. succinogenes, for example, which is one of the work horses for the production of SA, is not affected by the presence of toxic by-products and high sugar concentrations in the medium (Lin et al., 2008; Bradfield et al., 2015).

B. succiniciproducens BPP7, recently isolated by Ventorino et al. (2017), showed a rather long lag-phase $(24 \mathrm{~h})$ on $90 \%$ concentrated Arundo donax hydrolysate that strongly affected process productivity (Cimini et al., 2016). The study of strain physiology in the presence of common lignocellulose degradation 
products such as furfural hydroxymethylfurfural, 4-hydroxic benzoic acid, and vanillin demonstrated that growth and sugar consumption rates were not altered in mock $A$. donax hydrolysate. On the other hand, medium supplementation with a 10-fold higher concentration of inhibitors was accompanied by lower glucose and SA consumption and production rates in the first $8 \mathrm{~h}$ of growth; moreover, a critical threshold of about $12 \mathrm{~g} / \mathrm{l}$ of acetic acid was found to fully block growth for $24 \mathrm{~h}$ (Cimini et al., 2016). This indicated not only a sensitivity of $B$. succiniciproducens to high titers of these compounds but also a "short-term" ability to adapt that, thereby, reduces productivity but increases overall process yields (Cimini et al., 2016). Diluting the A. donax hydrolysate to $30 \%-50 \%$ B. succiniciproducens BPP7 demonstrated coconsumption of the main sugars, glucose and xylose (on average in a 1.85:1 ratio), in controlled 48 - $\mathrm{h}$ batch processes with constant $\mathrm{CO}_{2}$ sparging (Table 1); a yield of about $0.75 \mathrm{~mol} /$ $\mathrm{mol}$ and an increased productivity of $0.35 \mathrm{~g} / \mathrm{lh}$ were observed and confirmed during pre-pilot (150l bioreactor) fermentations (Cimini et al., 2016). In fact, a crucial step in biotechnological development is process scale up, and although different companies are engaged in the development of profitable SA production processes from non-fossil resources, this is the only example of SA production beyond laboratory scale from B. succiniciproducens present in the literature to date.

To further improve production titers and evaluate the global process efficiency, fed-batch experiments were also set up on prepilot scale using $A$. donax hydrolysate; SA titers increased by $76 \%$ and $146 \%$ by using $A$. donax hydrolysate or glucose during the feed phase, respectively (Cimini et al., 2019). Interestingly, higher glucose:xylose ratios in the feed reduced the production of contaminating acid by-products in favor of SA, indicating that glucose-rich hydrolysates should be preferred for large-scale production. Performance assessment of the overall process was also studied through material flow analysis, an interesting tool in industrial development. Data indicated a yield of SA per kilogram of biomass of about $88.5 \%$, and of about $52 \%$ on the total generated output (Cimini et al., 2019).

Batch fermentations on concentrated DDAPH (deacetylated dilute acid-pretreated hydrolysate) from corn stover demonstrated the ability of B. succiniciproducens CCUG 57335 to grow on a xylose-rich substrate and reach a final $\mathrm{Y}_{\mathrm{SA} / \mathrm{C}}$ of about 0.68-0.69 g/g (Salvachúa et al., 2016). The authors found a prolonged lag phase probably correlated to the detoxification of inhibitory molecules (e.g., furfural) and a different distribution of organic acids produced; in fact, a 2:1 ratio of acetate to formate and a high amount of lactic acid were observed. In particular, xylose-only media show the highest production of LA, indicating a different redox and ATP energy metabolism on different sugars (Becker et al., 2013; Salvachúa et al., 2016).

Simple batch experiments demonstrated the suitability of Populus nigra and Panicum virgatum as substrates for growth of B. succiniciproducens BPP7 (Pennacchio et al., 2018). Hydrolysates obtained with commercial cellulases and xylanases mixtures or with recombinant enzymes secreted from Strepromyces flavorgriseus were diluted (50\%) to increase process productivity resulting in starting glucose and xylose concentrations of about $18-20$ and $2-3 \mathrm{~g} / \mathrm{l}$ for $P$. nigra with a final production of about $15-18 \mathrm{~g} / \mathrm{l}$ of SA (Pennacchio et al., 2018). Although a lower amount of fermentable sugars was obtained from $P$. virgatum biomasses, high yield and productivities of $0.89 \mathrm{~g} / \mathrm{g}$ and $0.77 \mathrm{~g} / \mathrm{lh}$, respectively, were achieved from B. succiniciproducens BPP7 on this feedstock.

\section{Waste Streams}

In the search for cheaper processes, Babaei et al. (2019) for the first time used the organic fraction of kitchen household waste (OFKHW) in combination with raw biogas for $\mathrm{CO}_{2}$ supply. By studying glucose inhibition on $B$. succiniciproducens in bottle experiments, the authors found that at lower sugar concentration $(17 \mathrm{~g} / \mathrm{l})$, more glucose allocates to SA. In fact, at starting concentrations of about $60 \mathrm{~g} / \mathrm{l}$, differently from $A$. succinogenes, the spectrum of by-products produced by $B$. succiniciproducens changes in favor of lactic acid (SA:LA:FA: AA, B. succiniciproducens 0.56:0.25:0.07:0.2; A. succinogenes 0.56: $0.05: 0.08: 0.32)$. Moreover, interestingly, it was observed that the glucose concentration only affects the type of by-product produced, whereas the total energy (54\%) gained from glucose and channeled to product synthesis stays constant. Therefore, although enzymatic hydrolysis produced a sugar-rich substrate (about $120 \mathrm{~g} / \mathrm{l}, 85 \%$ glucose), the latter was diluted before batch fermentations, resulting in a final yield of about $0.25 \mathrm{~g} / \mathrm{g}$ of SA.

Stylianou and colleagues (2020) evaluated the organic fraction of municipal solid waste (OFMSW) separated in central management facilities for SA production from $B$. succiniciproducens JF4016. Major components of the liquid fraction obtained following mechanical pretreatment and enzymatic hydrolysis were glucose (70\%-81\%), xylose $(7 \%-13 \%)$, and fructose $(0 \%-14 \%)$, accompanied by significant concentrations of lactic and acetic acid that reached up to 18.6 and $3.7 \mathrm{~g} / \mathrm{l}$, respectively, whereas no furfural and hydroxymethyl furfural were found. Batch fermentations in controlled conditions on 1-liter reactors were performed with a concentration of total sugars ranging from 30 up to $80 \mathrm{~g} / \mathrm{l}$, reaching a maximum titer of about $37 \mathrm{~g} / \mathrm{l}$ in the tank. The authors found that higher total carbon source concentrations decreased the acid by-product-toSA ratio especially in the case of glucose-based fermentations (Stylianou et al., 2020), as previously observed for A. succinogenes (Ventrone et al., 2020).

Another example of waste stream valorization is that resulting from the use of spent sulfite liquor (SSL), a xyloserich aqueous substrate resulting from the sulfite wood pulping process. The use of untreated SSL strongly decreased the yield of SA and the overall process productivity; therefore, Pateraki and collaborators (2016a) partially purified SSL from toxic components, such as lignosulfonates, by ultra (UF) and nano-filtration (NF) to use the permeates as $\mathrm{C}$ source during fed-batch experiments. Higher SA titers were found on nanofiltered SSL, although the lowest TA:SA ratio was obtained by using the UF permeate as substrate (Pateraki et al., 2016a). Growth of B. succiniciproducens on sugar mixtures (total sugars from 1 to $69 \mathrm{~g} / \mathrm{l}$ ) simulating SSL composition, demonstrated that the SA yield drops if the concentration of total sugars in the medium is higher than 


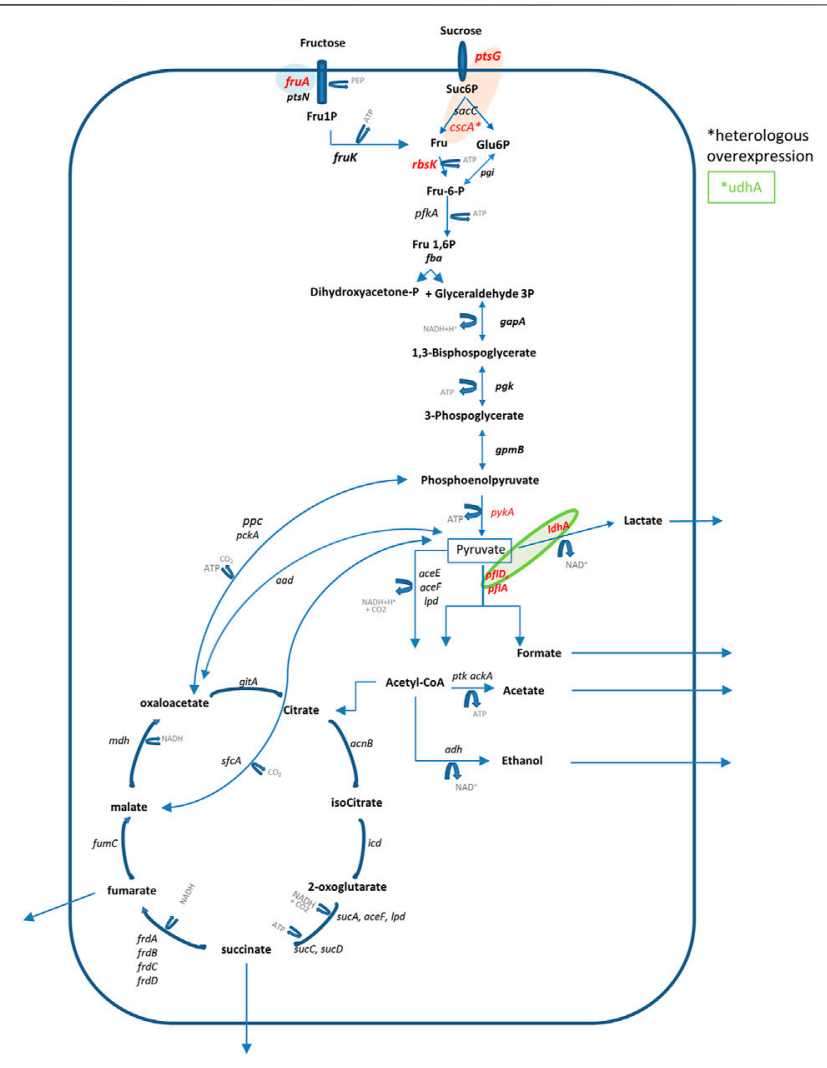

FIGURE 1 | Pathways leading to succinic acid production in $B$. succiniciproducens and main metabolic engineering gene targets discussed in the review. Colors indicate single or coupled gene targets. *Indicates heterologous overexpression.

$36 \mathrm{~g} / \mathrm{l}$; this is accompanied by an increased production of LA (Pateraki et al., 2016b). On the other hand, higher sugar concentrations decrease the yield of acetic and formic acid, as observed for $A$. succinogenes on the same medium. The presence of about $65 \mathrm{~g} / \mathrm{l}$ of total sugars in the medium caused a prolonged lag phase and an incomplete consumption of the carbon sources. Moreover, growth inhibition, either caused by single acid by-products or by the synergistic effect of mixtures of acids, was also investigated and observed at total acid concentrations of about $35 \mathrm{~g} / \mathrm{l}$ (Pateraki et al., 2016b). The effect on growth of individual organic acids indicated greater strain tolerance towards lactic acid (58 g/l) and SA (55 g/l). A similar result was also obtained by Cimini et al. (2019) that found zero growth at a concentration of SA equal to $60 \mathrm{~g} / \mathrm{l}$ on a glucose semidefined medium, and data fitting the Luong model of exponential inhibition.

An integrated biorefinery approach demonstrated the possibility to obtain more added value products simultaneously from SSL by combining nanofiltration and solvent extraction to further reduce the amount of lignosulfonates (Alexandri et al., 2016). This strategy improved growth of B. succiniciproducens in batch and fed-batch 1-liter processes leading to the obtainment of $39 \mathrm{~g} / \mathrm{l}$ of SA in about $127 \mathrm{~h}$, and to the recovery of phenolic compounds and about $90 \%$ of lignosulfates present in the waste material (Alexandri et al., 2016). Immobilization of B. succiniciproducens in alginate beads and fed-batch fermentation on diluted and nanofiltered SSL further improved production of SA (about $45 \mathrm{~g} / \mathrm{l}$ ), resulting in the best strain performance on xylose-rich substrates (Alexandri et al., 2017). Although the reuse of the cell catalyst showed reduced efficiency in repeated fermentation cycles, overall, this is a starting point for the development of an industrial approach that uses challenging waste biomass and immobilized $B$. succiniciproducens cells for SA production.

\section{DISCUSSION}

The future development of competitive biotech production processes of SA from renewable resources greatly depends on the performances of the microbial strains used as hosts for the production.

B. succiniciproducens demonstrated amenable to genetic manipulation also in addition to its already wide metabolic versatility. In fact, although it is not able to directly convert lignocellulose into fermentable monomers like few other microorganisms (Holwerda et al., 2019), it can metabolize all sugar moieties that are present in this raw material and also in others.

The strain demonstrates the ability to grow in the presence of toxic by-products released during lignocellulose pretreatments or recover after a short adaptation phase probably necessary to detoxify these compounds, similarly to A. succinogenes. Moreover, the investigation of the inhibitory effects of organic acids on growth in controlled $\mathrm{pH}$ conditions showed a high inhibition threshold (about $35 \mathrm{~g} / \mathrm{l}$, Pateraki et al., 2016b) even compared to other SA natural producer strains such as $M$. succiniciproducens (about $17 \mathrm{~g} / \mathrm{l}$, Hyohak et al., 2008) and A. succinogenes (33 g/l, Pateraki et al., 2016b). It is capable of growing on glucose-rich and also xylose-rich hydrolysates resulting in a different distribution of organic acids produced; differently from $A$. succinogenes, in the presence of high glucose concentrations or of excess xylose, a higher concentration of lactic acid is being produced (Babaei et al., 2019). On the other hand, when higher amounts of sugars are present, as observed for $A$. succinogenes, also the total carbon source concentration triggers changes in the organic acid product spectrum in favor of SA (Stylianou et al., 2020). Therefore, the choice of the material and the enzymatic treatment are of crucial importance in the final process output.

Overall, several metabolic features make B. succiniciproducens suitable for industrial production of SA; however, further investigation of economically viable solutions is still necessary. This requires rational engineering approaches based on the introduction of novel pathways, and/or on the improvement of the catalytic efficiency and energy utilization of the existing ones. Also, increasing tolerance to toxic compounds released during biomass pretreatment and hydrolysis would allow the use of more concentrated hydrolysates, thereby resulting in higher SA titers.

Few of the best SA production titers and productivities obtained by genetically modifying natural and non-natural 
producer strains (other than Basfia) are reported in Supplementary Table S1. Strains used on industrial scale are also included.

Two other aspects that were not discussed in the present work are also crucial for the development of sustainable SA biorefineries:

1) One of the major factors affecting SA production costs is the applied downstream process. Traditional separation and purification methods include different unit operations as precipitation, carbon treatments, extraction, chromatography, direct crystallization, and acidification, that have been combined to achieve recovery yields and purities of up to $80 \%$ and $>99.5 \%$, respectively (Cheng et al., 2012; Kumar et al., 2020). The use of multi-staged membrane systems that allow recycling of materials, cost reduction due to a lower number of necessary unit operations, and also a more environmentally sustainable approach, is an interesting alternative at industrial scale that was recently reviewed (Kumar et al., 2020). Product recovery accounts for $50 \%-70 \%$ of the overall production costs and therefore cost-effective solutions should be carefully considered.

2) Although, in 2020, the global SA market size was 141 million $\$$ and it is expected to reach 205.4 million $\$$ by the end of 2027 (Valuates Reports:https://www.prnewswire.com/news-releases/ succinic-acid-market-size-to-reach-usd-205-4-million-by-

2027-at-a-cagr-of-5-5-valuates-reports-301399416.html) due to the growing number of end-user applications, commercialization of bio-SA suffered a great downfall. Li and collaborators (Li and Mupondwa, 2021) demonstrated the importance of preliminary techno economic analyses for the identification of risks leading to unprofitable business plans.

\section{REFERENCES}

Ahn, J. H., Jang, Y.-S., and Lee, S. Y. (2016). Production of Succinic Acid by Metabolically Engineered Microorganisms. Curr. Opin. Biotechnol. 42, 54-66. doi:10.1016/j.copbio.2016.02.034

Ahn, J. H., Seo, H., Park, W., Seok, J., Lee, J. A., Kim, W. J., et al. (2020). Enhanced Succinic Acid Production by Mannheimia Employing Optimal Malate Dehydrogenase. Nat. Commun. 11, 1970-1981. doi:10.1038/s41467-02015839-z

Alexandri, M., Papapostolou, H., Komaitis, M., Stragier, L., Verstraete, W., Danezis, G. P., et al. (2016). Evaluation of an Integrated Biorefinery Based on Fractionation of Spent Sulphite Liquor for the Production of an Antioxidant-Rich Extract, Lignosulphonates and Succinic Acid. Bioresour. Techn. 214, 504-513. doi:10.1016/j.biortech.2016.03.162

Alexandri, M., Papapostolou, H., Stragier, L., Verstraete, W., Papanikolaou, S., and Koutinas, A. A. (2017). Succinic Acid Production by Immobilized Cultures Using Spent Sulphite Liquor as Fermentation Medium. Bioresour. Techn. 238, 214-222. doi:10.1016/j.biortech.2017.03.132

Babaei, M., Tsapekos, P., Alvarado-Morales, M., Hosseini, M., Ebrahimi, S., Niaei, A., et al. (2019). Valorization of Organic Waste with Simultaneous Biogas Upgrading for the Production of Succinic Acid. Biochem. Eng. J. 147, 136-145. doi:10.1016/j.bej.2019.04.012

Becker, J., Reinefeld, J., Stellmacher, R., Schäfer, R., Lange, A., Meyer, H., et al. (2013). Systems-wide Analysis and Engineering of Metabolic Pathway Fluxes in Bio-Succinate producingBasfia Succiniciproducens. Biotechnol. Bioeng. 110 (11), 3013-3023. doi:10.1002/bit.24963
The simulation, with a simplified model, of a 30,000 tons per year bio-SA production plant was used to potentially explain the failure of BioAmber by identifying, besides other factors, the operating cost of about 2.23 dollars $/ \mathrm{kg}$, which was 10 times higher than the predicted one.

\section{AUTHOR CONTRIBUTIONS}

DC drafted the manuscript and prepared the tables and figure; SD and AA collaborated in data search.

\section{FUNDING}

The fee was supported by the Ministero dell'Università e della Ricerca Scientifica (PON03PE_00107_1/1"Development of green technologies for production of BIOchemicals and their use in preparation and industrial application of POLImeric materials from agricultural biomasses cultivated in a sustainable way in Campania region-BioPoliS) funded in frame of the Operative National Programme Research and Competitiveness 2007-2013 D.D. Prot. N. 713/Ric. Del 29/10/20210. The grant for SD was funded by Altergon CDS 000463 . The grant for AA was funded by Bioteknet.

\section{SUPPLEMENTARY MATERIAL}

The Supplementary Material for this article can be found online at: https://www.frontiersin.org/articles/10.3389/fceng.2021.785691/ full\#supplementary-material

Boehmer, N., Haefner, S., Hoff, B., Schroeder, H., Schroeder, A. C., Wittmann, C., et al. (2019). Modified Microorganism for Improved Production of Succinate. Ludwigshafen and Rhein (DE): World intellectual property WO2019/ 122144A1.

Bradfield, M. F. A., Mohagheghi, A., Salvachúa, D., Smith, H., Black, B. A., Dowe, N., et al. (2015). Continuous Succinic Acid Production by Actinobacillus Succinogenes on Xylose-Enriched Hydrolysate. Biotechnol. Biofuels. 8, 181. doi:10.1186/s13068-015-0363-3

Cheng, K.-K., Zhao, X.-B., Zeng, J., Wu, R.-C., Xu, Y.-Z., Liu, D.-H., et al. (2012). Downstream Processing of Biotechnological Produced Succinic Acid. Appl. Microbiol. Biotechnol. 95, 841-850. doi:10.1007/s00253-012-4214-x

Cimini, D., Argenzio, O., D’Ambrosio, S., Lama, L., Finore, I., Finamore, R., et al. (2016). Production of Succinic Acid from Basfia Succiniciproducens up to the Pilot Scale from Arundo donax Hydrolysate. Bioresour. Techn. 222, 355-360. doi:10.1016/j.biortech.2016.10.004

Cimini, D., Zaccariello, L., D’Ambrosio, S., Lama, L., Ruoppolo, G., Pepe, O., et al. (2019). Improved Production of Succinic Acid from Basfia Succiniciproducens Growing on A. donax and Process Evaluation through Material Flow Analysis. Biotechnol. Biofuels. 12, 22. doi:10.1186/s13068-019-1362-6

Dharmadi, Y., Murarka, A., and Gonzalez, R. (2006). Anaerobic Fermentation of Glycerol by Escherichia coli: a New Platform for Metabolic Engineering. Biotechnol. Bioeng. 94 (4), 821-829. doi:10.1002/bit.21025

Grabar, T., Gong, W., and Yocum, R. R. (2012). Metabolic Evolution of Escherichia coli Strains that Produce Organic Acids. United States Patent U.S. No 20120202259A1.

Holwerda, E. K., Worthen, R. S., Kothari, N., Lasky, R. C., Davison, B. H., Fu, C., et al. (2019). Multiple Levers for Overcoming the Recalcitrance of 
Lignocellulosic Biomass. Biotechnol. Biofuels. 12, 12-15. doi:10.1186/s13068019-1353-7

Hyohak, S., Jang, S. H., Park, J. M., and Lee, S. Y. (2008). Modeling of Batch Fermentation Kinetics for Succinic Acid Production by Mannheimia Succiniciproducens. Biochem. Eng. J. 40 (1), 107-115. doi:10.1016/j.bej.2007.11.021

Krawczyc, J. M., Haefner, S., Schroder, H., Dantas Costa, E., Zelder, O., and Von Abendroth, G. (2015a). Modified Microorganism for Improved Production of fine Chemicals on Sucrose. Ludswigshafen (DE): World intellectual property WO 2016/030373 A1.

Krawczyc, J. M., Haefner, S., Schroder, H., Dantas Costa, E., Zelder, O., Von Abendroth, G., et al. (2015b). Improved Miocroorganisms for Succinic Acid Production. Ludwigshafen (DE): World intellectual property WO 2015/ 117916A1.

Kuhnert, P., Scholten, E., Haefner, S., Mayor, D., and Frey, J. (2010). Basfia Succiniciproducens Gen. nov., Sp. nov., a New Member of the Family Pasteurellaceae Isolated from Bovine Rumen. Int. J. Syst. Evol. Microbiol. 60, 44-50. doi:10.1099/ijs.0.011809-0

Kumar, R., Basak, B., and Jeon, B.-H. (2020). Sustainable Production and Purification of Succinic Acid: A Review of Membrane-Integrated green Approach. J. Clean. Prod. 277, 123954-123973. doi:10.1016/ j.jclepro.2020.123954

Lange, A., Becker, J., Schulze, D., Cahoreau, E., Portais, J.-C., Haefner, S., et al. (2017). Bio-based Succinate from Sucrose: High-Resolution 13C Metabolic Flux Analysis and Metabolic Engineering of the Rumen Bacterium Basfia Succiniciproducens. Metab. Eng. 44, 198-212. doi:10.1016/j.ymben.2017.10.003

Lee, S. J., Song, H., and Lee, S. Y. (2006). Genome-based Metabolic Engineering of Mannheimia Succiniciproducens for Succinic Acid Production. Appl. Environ. Microbiol. 72 (3), 1939-1948. doi:10.1128/aem.72.3.1939-1948.2006

Li, X., and Mupondwa, E. (2021). Empirical Analysis of Large-Scale Bio-Succinic Acid Commercialization from a Technoeconomic and Innovation Value Chain Perspective: BioAmber Biorefinery Case Study in Canada. Renew. Sustain. Energ. Rev. 137, 110587-110602. doi:10.1016/j.rser.2020.110587

Lin, S. K. C., Du, C., Koutinas, A., Wang, R., and Webb, C. (2008). Substrate and Product Inhibition Kinetics in Succinic Acid Production by Actinobacillus Succinogenes. Biochem. Eng. J. 41 (2), 128-135. doi:10.1016/j.bej.2008.03.013

Litsanov, B., Brocker, M., and Bott, M. (2012). Toward Homosuccinate Fermentation: Metabolic Engineering of Corynebacterium Glutamicum for Anaerobic Production of Succinate from Glucose and Formate. Appl. Environ. Microbiol. 78, 3325-3337. doi:10.1128/aem.07790-11

Markets Study Report (2021). From Markets and Markets Global Succinic Acid Market Size Study, by Type (Bio-Based and Petro-Based) by Application (Food and Beverage, Pharmaceutical, Industrial and Other) and Regional Forecasts 2021-2027. Available at: https://www.marketstudyreport.com/reports/globalsuccinic-acid-market-size-research?utm_source=Marketwatchtm.com/\&utm_ medium $=\mathrm{AK}$.

McCoy, M. (2019). Succinic Acid, once a Biobased Chemical star, Is Barely Being Made. From Chemical and engineering news. Available at: https://cen.acs.org/ business/biobased-chemicals/Succinic-acid-once-biobased-chemical/97/i12.

McKinlay, J. B., Zeikus, J. G., and Vieille, C. (2005). Insights into Actinobacillus Succinogenes Fermentative Metabolism in a Chemically Defined Growth Medium. Appl. Environ. Microbiol. 71 (11), 6651-6656. doi:10.1128/ AEM.71.11.6651-6656.2005

Pateraki, C., Almqvist, H., Ladakis, D., Lidén, G., Koutinas, A. A., and Vlysidis, A. (2016b). Modelling Succinic Acid Fermentation Using a Xylose Based Substrate. Biochem. Eng. J. 114, 26-41. doi:10.1016/j.bej.2016.06.011

Pateraki, C., Ladakis, D., Stragier, L., Verstraete, W., Kookos, I., Papanikolaou, S., et al. (2016a). Pretreatment of Spent Sulphite Liquor via Ultrafiltration and Nanofiltration for Bio-Based Succinic Acid Production. J. Biotechnol. 233, 95-105. doi:10.1016/j.jbiotec.2016.06.027
Pennacchio, A., Ventorino, V., Cimini, D., Pepe, O., Schiraldi, C., Inverso, M., et al. (2018). Isolation of New Cellulase and Xylanase Producing Strains and Application to Lignocellulosic Biomasses Hydrolysis and Succinic Acid Production. Bioresour. Techn. 259, 325-333. doi:10.1016/ j.biortech.2018.03.027

Rush, B. J., and Fosmer, A. M. (2014). Methods for Succinate Production. Luxembourg (LU): United States Patent U.S. No 20140363862A1.

Salvachúa, D., Smith, H., St. John, P. C., Mohagheghi, A., Peterson, D. J., Black, B. A., et al. (2016). Succinic Acid Production from Lignocellulosic Hydrolysate by Basfia Succiniciproducens. Bioresour. Techn. 214, 558-566. doi:10.1016/ j.biortech.2016.05.018

Scholten, E., Dagele, D., Haefner, S., and Schroder, H. (2008). Bacterial Strain and Process for the Fermentative Production of Organic Acids. United States Patent U.S. No 8 (574), 875-B2.

Scholten, E., and Dägele, D. (2008). Succinic Acid Production by a Newly Isolated Bacterium. Biotechnol. Lett. 30 (12), 2143-2146. doi:10.1007/s10529-0089806-2

Scholten, E., Renz, T., and Thomas, J. (2009). Continuous Cultivation Approach for Fermentative Succinic Acid Production from Crude Glycerol by Basfia Succiniciproducens DD1. Biotechnol. Lett. 31, 1947-1951. doi:10.1007/s10529009-0104-4

Schroder, H., Haefner, S., Von Abendroth, G., Hollmann, R., Raddatz, A., Ernst, H., et al. (2010). Microbial Succinic Acid Producers and Purification of Succinic Acid. United States Patent U.S. No 8 (673), 598-B2.

Stylianou, E., Pateraki, C., Ladakis, D., Cruz-Fernández, M., Latorre-Sánchez, M., Coll, C., et al. (2020). Evaluation of Organic Fractions of Municipal Solid Waste as Renewable Feedstock for Succinic Acid Production. Biotechnol. Biofuels. 13, 72. doi:10.1186/s13068-020-01708-w

Vemuri, G. N., Eiteman, M. A., and Altman, E. (2002). Succinate Production in Dual-phase Escherichia coli Fermentations Depends on the Time of Transition from Aerobic to Anaerobic Conditions. J. Ind. Microbiol. Biotechnol. 28, 325-332. doi:10.1038/sj.jim.7000250

Ventorino, V., Robertiello, A., Cimini, D., Argenzio, O., Schiraldi, C., Montella, S., et al. (2017). Bio-Based Succinate Production from Arundo donax Hydrolysate with the New Natural Succinic Acid-Producing Strain Basfia Succiniciproducens BPP7. Bioenerg. Res. 10, 488-498. doi:10.1007/s12155017-9814-y

Ventrone, M., Schiraldi, C., Squillaci, G., Morana, A., and Cimini, D. (2020). Chestnut Shells as Waste Material for Succinic Acid Production from Actinobacillus Succinogenes 130Z. Fermentation 6, 105-115. doi:10.339/ fermentation604010510.3390/fermentation6040105

Conflict of Interest: The authors declare that the research was conducted in the absence of any commercial or financial relationships that could be construed as a potential conflict of interest.

Publisher's Note: All claims expressed in this article are solely those of the authors and do not necessarily represent those of their affiliated organizations, or those of the publisher, the editors, and the reviewers. Any product that may be evaluated in this article, or claim that may be made by its manufacturer, is not guaranteed or endorsed by the publisher.

Copyright (๑ 2021 D'ambrosio, Alfano and Cimini. This is an open-access article distributed under the terms of the Creative Commons Attribution License (CC BY). The use, distribution or reproduction in other forums is permitted, provided the original author(s) and the copyright owner(s) are credited and that the original publication in this journal is cited, in accordance with accepted academic practice. No use, distribution or reproduction is permitted which does not comply with these terms. 